\title{
Correlation between Patterns of Mdm2 SNIP 309 and Histopathological Severity of Helicobacter pylori Associated Gastritis in Thailand
}

\author{
Taweesak Tongtawee ${ }^{1,4 *}$, Chavaboon Dechsukhum ${ }^{3,4}$, Krajang Talabnin $^{8}$,Wilairat \\ Leeanansaksiri $^{7}$, Soraya Kaewpitoon ${ }^{2,4}$, Natthawut Kaewpitoon ${ }^{5,6}$, Ryan A Loyd $^{2,4}$, \\ Likit Matrakool ${ }^{1,4}$, Sukij Panpimanmas ${ }^{1,4}$
}

\begin{abstract}
Background: The commonly held view of the tumor suppressor p53 is as a regulator of cell proliferation, apoptosis and many other biological processes as well as external and internal stress responses. Mdm2 SNIP309 is a negative regulator of $\mathrm{p} 53$. Therefore, this study aimed to determine the correlation between the patterns of Mdm2 SNIP 309 and the inflammation grading of Helicobacter pylori associated gastritis in a Thai population. Materials and Methods: A cross-sectional study was carried out from November 2014 through June 2015. Biopsy specimens were obtained from infected patients and infection was proved by positive histology. The gastric mucosa specimens were sent to the Molecular Genetic Unit, Institute of Medicine, Suranaree University of Technology where they were tested by molecular methods to detect the patterns of Mdm2 SNIP 309 using the real-time PCR hybridization probe method. The results were analyzed and compared with the Updated Sydney classification. Results: A total of 100 infected patients were interviewed and gastric mucosa specimens were collected. In this study the percentage of Mdm2 SNIP 309 T/T homozygous and Mdm2 SNIP309 G/T heterozygous was 78\% and $19 \%$ respectively whereas Mdm2 SNIP309 G/G homozygous was 3\%. Mdm2 SNIP 309 T/T homozygous and Mdm2 SNIP309 G/T heterozygous correlated with mild to moderate inflammation $(P<0.01)$ whereas Mdm2 SNIP309 G/G homozygous correlated with severe inflammation $(P<0.01)$. Conclusions: Our study found the frequency of Mdm2 SNP309 G/G in our Thai population to be very low, and suggests that this can explain to some extent the low incidence of severe inflammation and gastric cancer changes in the Thai population. Mild to moderate inflammation are the most common pathologic gradings due to the unique genetic polymorphism of Mdm2 SNIP 309 in the Thai population.
\end{abstract}

Keywords: Mdm2 SNIP 309 - Inflammation grading - Helicobacter pylori - Gastric cancer

Asian Pac J Cancer Prev, 16 (17), 7781-7784

\section{Introduction}

Our understanding of the tumor suppressor p53 as a regulator of cell proliferation, apoptosis and senescence has expanded greatly in recent years to cover many biological processes as well as external and internal stress responses, and immune-related processes, especially as relates to cancer. A variety of interactions between $\mathrm{p} 53$ and the immune stress systems are currently being investigated that suggest opportunities to utilize p53 in modulating immunological activities (Lowe et al., 2013).

Mdm2 was discovered in 1992 to bind to, and negatively regulate, transactivation of $\mathrm{p} 53$, and was then itself found to be a transcriptional target of p53, defining a negative feedback loop (Momand et al., 1993; Picksley and Lane, 1993). Mdm2 proved to be an E3 ubiquitin ligase, stimulating p53 degradation (Haupt et al., 1997; Honda et al., 1997; Kubbutat et al., 1997).

Cancer of the stomach is the fifth most common human cancer worldwide. Intriguingly, marked variation in the gastric cancer incidence is observed. The highest incidence of gastric cancer is found in Asia such as Korea $(41.8 / 100,000)$ whereas the lowest incidence is found in Africa and Northern America. In the Thai population, the incidence of gastric cancer is only 3.5/100,000. As chronic gastritis is the major predisposing condition to gastric cancer, the association study between these conditions has become an area of interest. However, in Thailand where the gastric cancer incidence falls into the low-risk country group, the prevalence of Helicobacter pylori associated gastritis is intriguingly high. Thailand is one area of the enigmatic situation also reported in

${ }^{1}$ Department of Surgery, ${ }^{2}$ Family Medicine and Community Medicine, ${ }^{3}$ Pathological Unit, ${ }^{8}$ Medical Technology and Medical Biochemistry, Institute of Medicine, ${ }^{5}$ Parasite Research Unit, ${ }^{7}$ Institute of Science, Suranaree University of Technology, ${ }^{4}$ Suranaree University of Technology Hospital, ${ }^{6}$ Faculty of Public Health, Vongchawalitkul University, Nakhonrachasima, Thailand *For correspondence: taweesak.t@sut.ac.th 
Africa (Holcombe, 1992). Many studies have investigated the association between Helicobacter pylori infection and gastric cancer in Asia. A study from India failed to demonstrate an association between Helicobacter pylori infection and gastric cancer (Sivaprakash et al., 1996; Kate et al., 1998; Kate et al., 2000; Khanna et al., 2002) whereas studies from China and Japan demonstrated an association between Helicobacter pylori infection and gastric cancer (Asaka et al., 1995; Cai et al., 2000). The clinical data concerning the role of Mdm2 SNP309 in gastric cancer development is limited. A case-control study among the Iranian gastric cancer population identified Mdm2 SNP309 as a risk factor for this cancer with an odds ratio $=2.08$ (95\% Confident interval=1.37-4.34) (Moradi et al., 2014). A similar study in a Chinese gastric cancer population also showed the same trend (Wang et al., 2009). We are interested in pursuing clinical study in the Thai population to evaluate the possible association between Mdm2 SNP309 and inflammation grading. As the inflammatory process is also influenced by p53, we also evaluated the possible association between this SNP and the degree of chronic gastritis associated with Helicobacter pylori, which is the precursor lesion for gastric cancer.

\section{Materials and Methods}

\section{Patients}

A total of 100 patients with histology diagnosed Helicobacter pylori associated gastritis had gastric tissue collected to participate in this study from November 2014 through June 2015. The study was performed in accordance with good clinical practice and the guidelines of the Declaration of Helsinki. All patients provided written informed consent and the study protocol was approved by the Ethics Committee for Research Involving Human Subjects, Suranaree University of Technology (EC-57-34).

\section{Biopsy specimens}

Four biopsy samples were taken directly from the observation sites (Taweesak et al., 2015). Two samples were sent for histological analysis and 2 were used for rapid urease testing on site (Prontodyle, GASTREX, France).

\section{Histological analysis}

Gastric tissue specimens were sent to the pathologist for histological analysis. The hematoxylin and eosin stain and the Giemsa stain were used for identification of Helicobacter pylori. The pathological analysis was made by 5 pathologists at Bangkok Pathological Laboratory outside of Suranaree University of Technology according to the Updated Sydney classification (Dixon et al., 1996) (Table 1), including evaluation of chronic inflammation, atrophy, intestinal metaplasia, and activity of gastritis.

\section{DNA isolation method}

The DNA from the gastric mucosa of infected patients was extracted from frozen gastric tissue biopsy specimens which were stored at a temperature of less than $-20^{\circ} \mathrm{C}$ using the QIAamp DNA FFPE tissue kit (Qiagen, USA). The DNA extraction was performed according to the manufacturer protocol. Briefly, ten tissue sections each 5 $\mu \mathrm{M}$ thick were collected in $1.5 \mathrm{ml}$ micro centrifuge tubes. The tissue specimens were placed in a microcentrifuge tube, and buffer ATL $(180 \mu \mathrm{L})$ and proteinase K $(20 \mu \mathrm{L})$ were added. The samples were mixed by vortexing and incubated at $56^{\circ} \mathrm{C}$ until the tissues were completely lysed. Buffer AL $(200 \mu \mathrm{L})$ was added to the samples, which were subsequently incubated at $70^{\circ} \mathrm{C}$ for 10 minutes. Next, 240 $\mu \mathrm{L}$ of $100 \%$ ethanol was added to the samples, which were mixed by vortexing for 15 seconds. Each sample was placed in a QIAamp spin column and centrifuged at $8000 \mathrm{rpm}$ for 1 minute. The columns were washed with AW1 buffer $(500 \mu \mathrm{L})$, and samples were centrifuged at $8000 \mathrm{rpm}$ for 1 minute. AW2 buffer $(500 \mu \mathrm{L})$ was added to the column, and samples were centrifuged at 14,000 rpm for 3 minutes. Buffer AE $(200 \mu \mathrm{L})$ was added to each sample, and samples were incubated for 1 minute prior to centrifugation at $8000 \mathrm{rpm}$ for 1 minute. Finally, the DNA was extracted from the tissue.

\section{Polymorphism analysis}

MDM2 SNP309 genotypes were analyzed using real-time PCR. The hybridization probes (light-cycler probe) were utilized for this analysis. The real-time PCR procedure was accomplished by using a LightCycler ${ }^{\circledR}$ 480 instrument (Roche diagnostics, Neuilly sur Seine, France). The identifications of target PCR products were accomplished by melting curve analyses. The target

\section{Table 2. The Patient Demographic Data}

\begin{tabular}{lc}
\hline Demographics data & $\mathrm{n}=100$ \\
\hline Male/female (n) & $14 / 86$ \\
Mean age (years) & 57.2 \\
Peptic ulcer disease (GU/DU) & $13 \%$ \\
Gastric cancer & $1 \%$ \\
Non ulcer gastritis/duodinitis & $86 \%$ \\
SNP 309 T/T & $78 \%$ \\
SNP309 G/T & $19 \%$ \\
MDM2 SNP309 G/G & $3 \%$ \\
\hline
\end{tabular}

\section{Table 1. Updated Sydney System}

\begin{tabular}{|c|c|c|c|c|}
\hline Histologic properties & & $\begin{array}{l}\text { Definition } \\
\text { mild }\end{array}$ & $\begin{array}{l}\text { Grade } \\
\text { moderate }\end{array}$ & severe \\
\hline Chronic inflammation & Lymphocyte and plasma cell in lamina propria & $1+$ & $2+$ & $3+$ \\
\hline Neutrophil activation & Neutrophilic infiltration in lamina propria or superficial epithelium & $<1 / 3$ & $1 / 3-2 / 3$ & $>2 / 3$ \\
\hline Glandular atrophy & Loss of corpus and antral glands & $1+$ & $2+$ & $3+$ \\
\hline Intestinal metaplasia & Intestinal metaplasia of mucosal epithelium & $<1 / 3$ & $1 / 3-2 / 3$ & $>2 / 3$ \\
\hline Helicobacter pylori & Helicobacter pylori intensity & $1+$ & $2+$ & $3+$ \\
\hline
\end{tabular}


PCR products were amplified by using the primers as reported in the previous literature. The hybridization probes included the one that was in the SNP309 (the sensor probe). This sensor probe is labeled by LC-red 640 at 5' and phosphorylated at 3'. The anchor probe was hybridized to the PCR product at the site $3 \mathrm{bp}$ upstream from the sensor probe. $3 \mu 1$ of DNA templates were subjected to PCR reaction in the final volume of 20 $\mu 1$. The reaction mixture consisted of $\mathrm{MgCl} 2(25 \mathrm{mM})$, forward and reverse primers (20 $\mathrm{M}$ each), sensor and anchor probes (20 M each), and $2 \mu \mathrm{l}$ of FastStart DNA Master Hybridization Probes (Roche Diagnostics). PCR amplification comprised an initial denaturation cycle at $95^{\circ} \mathrm{C}$ for $10 \mathrm{~min}$, followed by 50 amplification cycles (with a temperature transition rate of $20^{\circ} \mathrm{C} / \mathrm{s}$ ) consisting of $95^{\circ} \mathrm{C}$ for $0 \mathrm{~s}$, annealing at $60^{\circ} \mathrm{C}$ for $10 \mathrm{~s}$, and extension at $72^{\circ} \mathrm{C}$ for $17 \mathrm{~s}$. After amplification a melting step was performed, consisting of $95^{\circ} \mathrm{C}$ for $0 \mathrm{~s}$, cooling to $45^{\circ} \mathrm{C}$ for $30 \mathrm{~s}$ (with a temperature transition rate of $20^{\circ} \mathrm{C} / \mathrm{s}$ ), and finally a slow rise in the temperature to $85^{\circ} \mathrm{C}$ at a rate of $0.1^{\circ} \mathrm{C} / \mathrm{s}$ with continuous acquisition of fluorescence decline. The genotype of each patient was categorized into three genotypes SNP309 G/G homozygous, T/T homozygous and $\mathrm{G} / \mathrm{T}$ heterozygous based on the different melting curves.

\section{Statistical analysis}

SPSS for Windows (version 16.0; SPSS, Chicago, IL, USA) was used for the statistical analysis; baseline demographic data as well as the correlation between Mdm2 SNIP 309 and the inflammation grading of the infected patients were analyzed. The patterns of genetic polymorphism were analyzed by using the LightCycler ${ }^{\circledR}$ 480 instrument (Roche diagnostics, Neuilly sur Seine, France).

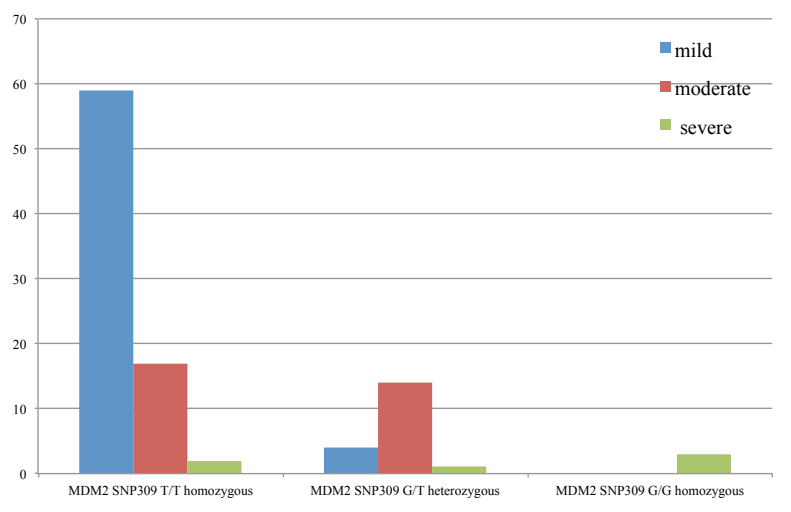

Figure 1.Pattern of MDM2 SNIP309 and Inflammation Grading

Table 3. Pattern of MDM2 SNIP 309 and Inflammation Grading Correlation

\begin{tabular}{lrrrrr}
\hline Pattern of MDM2 SNIP 309 & \multicolumn{5}{c}{$\begin{array}{c}\text { Inflamation grading } \\
\text { mild }\end{array}$} \\
\hline MDModerate & severe \\
\hline MDM2 SNP309 T/T homozygous & 59 & 17 & 2 & $\mathrm{P}<0.01$ \\
MDM2 SNP309 G/T heterozygous & 4 & 14 & 1 & $\mathrm{P}<0.01$ \\
\hline
\end{tabular}

\section{Results}

A total of 100 patients with histology diagnosed Helicobacter pylori associated gastritis had gastric tissue collected. Male patients were $14 \%$ and female $86 \%$, mean age was 57.2 years, peptic ulcer disease (GU/DU) was $13 \%$, non-ulcer gastritis/duodinitis was $86 \%$ and gastric cancer was $1 \%$. The patients' demographic data are summarized in Table 2. Mdm2 SNIP 309 T/T homozygous and Mdm2 SNIP309 G/T heterozygous correlated with mild to moderate inflammation $(\mathrm{P}<0.01)$ whereas $\mathrm{Mdm} 2$ SNIP309 G/G homozygous correlated with severe inflammation $(\mathrm{P}<0.01)$. The correlation between $\mathrm{Mdm} 2$ SNIP 309 and the inflammation grading was summarized in Table 3 and Figure 1.

\section{Discussion}

Helicobacter pylori associated gastritis and gastric cancer remains a major health problem in Asia, including China, Japan, and Thailand (Holcombe et al., 1992; Asaka et al., 1993; Cai et al., 2000). Cancer occurs through damage to the cell cycle, especially the tumor suppressor p53 as well as Mdm2 SNIP309, the negative regulator of $\mathrm{p} 53$. Besides the well-established role of MDM2 in carcinogenesis via the p53-dependent pathway, Mdm2 has been shown to be involved in inflammatory processes. With regard to this pro-inflammatory property, a Mdm2 has p53-independent activation property for nuclear factor-kappa beta (NF)B). Due the fact that p53 and nuclear factor-kappa beta $(\mathrm{NF} x \mathrm{~B})$ are to reciprocal negative regulatory partners, inflammation and carcinogenesis are linked together. It has been shown that persistent activation of NF $\mathrm{BB}$ during chronic inflammation can lead to cancer development through inhibition of p53 function (Gurova et al., 2005; O'Prey et al., 2010). Moreover, p53 has anti-inflammatory activity via NFxB inhibition (Komarova et al., 2005).

As Mdm2 can regulate both p53 and NF $\mathrm{B}, \mathrm{Mdm} 2$ altered expression likely contributes to both inflammation and carcinogenesis. According to this scenario, genetic polymorphism-mediated Mdm2 overexpression likely disturbs the physiologic balance of p53 and NFxB in that pro-inflammatory and hyper-proliferative states are preferable. For this reason, we hypothesize that the specific genetic polymorphism of the Mdm 2 gene (T309G gene polymorphism) with resulting Mdm2 overexpression is also likely associated with more severe inflammation in Helicobacter pylori associated gastritis. This study is the first to report the percentage of Mdm2 SNIP 309 T/T homozygous, Mdm2 SNIP309 G/T heterozygous, and Mdm2 SNIP309 G/G homozygous in Thai patients. Our study has demonstrated the association of Mdm2 SNP309 genotype and severity of inflammation in Helicobacter pylori infected gastric mucosa. The GG genotype of SNP309 enhanced the expression of Mdm2 RNA and protein (Tergaonkar et al., 2002; Bond et al., 2005). The severity of inflammation may be contributed to by the high expression of Mdm2 protein in the MdM2 SNP309 GG genotype. In addition; Mdm2 SNIP 309 T/T homozygosity and Mdm2 SNIP309 G/T heterozygosity were correlated 
Taweesak Tongtawee et al

with mild to moderate inflammation whereas Mdm2 SNIP309 G/G homozygousity was correlated with severe inflammation. This study suggests that there is a good correlation between Mdm2 SNP309 and gastric cancer development.

Conclusion: Our study suggests that the frequency of Mdm2 SNP309 G/G is very low among Thai people, which can explain to some extent the low incidence of severe inflammation and gastric cancer changes in the Thai population. The result shows a good correlation between pattern of Mdm2 SNIP 309 and inflammation grading. Mild to moderate inflammation is the most common pathologic grading due to the unique genetic polymorphism of Mdm2 SNIP 309 in the Thai population.

\section{Acknowledgements}

This study was supported by a grant for medical investigation from the Suranaree University of Technology and was approved by the Ethics Committee for Research Involving Human Subjects Suranaree University of Technology (EC-57-34).

\section{References}

Asaka M, Kato M, Kudo M, et al (1995). Relationship between Helicobacter pylori infection, atrophic gastritis and gastric carcinoma in a Japanese population. Eur J Gastroenterol Hepatol, 1, 7-10.

Bond GL, Hu W, Levine AJ, et al (2005). Mdm2 is a central node in the p53 pathway: 12 years and counting. Curr Cancer Drug Targets, 5, 3-8.

Cai L, Yu SZ, Zhang ZF, et al (2000). Helicobacter pylori infection and risk of gastric cancer in Changle County, Fujian Province, China. World J Gastroenterol, 6, 374-6.

Dixon MF, Genta RM, Harley JH, et al (1996). Classification and grading of gastritis: The updated Sydney system. Am J Surgical Pathol, 20, 1161-81.

Gurova KV, Hill JE, Guo C, et al (2005). Small molecules that reactivate $\mathrm{p} 53$ in renal cell Haupt, carcinoma reveals a nfkappab-dependent mechanism of p53 suppression in tumors. Proc Natl Acad Sci U. S. A, 102, 17448-53.

Haupt Y, Maya R, Kazaz A, et al (1997). Mdm2 promotes the rapid degradation of p53. Nature, 387, 296-9.

Honda R, Tanaka H, Yasuda H, (1997). Oncoprotein MDM2 is an ubiquitin ligase $\mathrm{E} 3$ for tumor suppressor p53. FEBS Letters, 420, 25-7.

Holcombe C (1992). Helicobacter pylori: the African enigma. Gut, 33, 429-31.

Kate V and Ananthakrishnan N (2000). Helicobacter pylori and gastric carcinoma: evidence for the link. Natl Med $J$ India, 13, 329.

Kate V,Ananthakrishnan N, Badrinath S, et al (1998). Prevalence of Helicobacter pylori infection in disorders of the upper gastrointestinal tract in south India. Natl Med J India, 11, 5-8.

Khanna AK, Seth P, Nath G, et al (2002). Correlation of Helicobacter pylori and gastric carcinoma.J Postgrad Med, 48, 27-8.

Komarova EA, Krivokrysenko V, Wang K, et al (2005). P53 is a suppressor of inflammatory response in mice. Faseb J Official Publicat Federation Of American Societies For Experimental Biol, 19, 1030-2.

Kubbutat MH and Jones SN (1997). Regulation of p53 stability by Mdm2. Nature, 387, 299-303.

Lowe J, Shatz M, Resnick MA, et al (2013). Modulation of immune responses by the tumor suppressor p53. Bio Discovery, $\mathbf{8}, 2$.

Momand J and Zambetti GP (1992). The mdm-2 oncogene product forms a complex with the $\mathrm{p} 53$ protein and inhibits p53-mediated transactivation. Cell, 69, 1237-45.

Moradi MT, Salehi Z, Aminian K, et al (2014). Effects of p53 codon 72 and MDM2 SNP309 polymorphisms on gastric cancer risk among the Iranian population. Asian Pac $J$ Cancer Prevc, 15, 7413-7.

O'Prey J, Crighton D, Martin AG, et al (2010). P53-mediated induction of noxa and p53aip1 requires nfkappab. Cell Cycle, 9, 947-52.

Picksley SM, Lane DP (1993). The p53-mdm2 autoregulatory feedback loop: a paradigm for the regulation of growth control by p53?. Bioessays, 15, 689-90.

Sivaprakash R, Rao UA, Thyagarajan SP, et al (1996). Investigation for the prevalence of hselicobacter pylori infection in patients with gastric carcinoma in Madras, India. Jpn J Med Sci Biol, 49, 49-56.

Taweesak T, Soraya K, Natthawut K, et al (2015). Correlation between gastric mucosal morphologic patterns and histopathological severity of helicobacter pylori associated gastritis using conventional narrow band imaging gastroscopy. Bio Med Res Int, 7, 42-8.

Tergaonkar V, Pando M, Vafa O, et al (2002). P53 stabilization is decreased upon nf kappa b activation : A role for nfkappab in acquisition of resistance to chemotherapy. Cancer Cell, 1, 493-503.

Wang X, Yang J, Ho B, et al (2009). Interaction of helicobacter pylori with genetic variants in the MDM2 promoter is associated with gastric cancer susceptibility in Chinese patients. Helicobacter, 14, 114-9. 